\title{
Internal languages of retrieval: The bilingual encoding of memories for the personal past
}

\author{
ROBERT W. SCHRAUF \\ Buehler Center on Aging, McGaw Medical Center of Northwestern University, Chicago, Illinois \\ and \\ DAVID C. RUBIN \\ Duke University, Durham, North Carolina
}

\begin{abstract}
In contrast to most research on bilingual memory that focuses on how words in either lexicon are mapped onto memory for objects and concepts, we focus on memory for events in the personal past. Using a word-cue technique in sessions devoted exclusively to one language, we found that older Hispanic immigrants who had come to the United States as adults internally retrieved autobiographical memories in Spanish for events in the country of origin and in English for events in the U.S. These participants were consistently capable of discerning whether a memory had come to them "in words" or not, reflecting the distinction between purely imagistic or conceptual memories and specifically linguistic memories. Via examination of other phenomenological features of these memories (sense of reliving, sensory detail, emotionality, and rehearsal), we conclude that the linguistic/nonlinguistic distinction is fundamental and independent of these other characteristics. Bilinguals encode and retrieve certain autobiographical memories in one or the other language according to the context of encoding, and these linguistic characteristics are stable properties of those memories over time.
\end{abstract}

Current models of bilingual memory typically consider how language elements (phonological, syntactic, semantic) are related to conceptual and imagistic memory stores. Revised hierarchy models of bilingual memory posit two (or more) interconnected lexicons, which have differential access to a conceptual, and presumably nonlinguistic, memory store (Kroll \& Curley, 1988; Kroll \& de Groot, 1997; Kroll \& Sholl, 1992; Kroll et al., 1992; Kroll \& Stewart, 1990, 1994). Connectionist models suggest that words in either of the lexicons activate patterns of networks in the conceptual store (de Groot, 1992, 1993; de Groot \& Comjis, 1995; de Groot \& Hoeks, 1995; de Groot $\&$ Nas, 1991). Both models emphasize linking words (lexemes) or their mental correlates (lemmas) with their mental referents. Both models assume an essentially nonlinguistic conceptual store for these mental referents. Both models tap into semantic memory and laboratory versions of episodic memory.

In contrast, we have been concerned not so much with how individual word elements are mapped onto semantic referents but rather with how larger mental narratives (personal memories) are linguistically encoded and retrieved from either of the bilingual's two languages (Schrauf, in press; Schrauf \& Rubin, 1997, 1998). Given the interrelation of narrative and language in autobio-

This research was supported by National Institute of Aging Grant IR01 AG16340-01A1. Correspondence concerning this article should be addressed to R. W. Schrauf, Buehler Center on Aging, McGaw Medical Center, Northwestern University, 750 North Lake Shore Drive, Suite 601, Chicago, IL 60611-2611 (e-mail:rschrauf@northwestern. edu). graphical memory (Rubin, 1998), we regard the nonlinguistic status of the underlying autobiographical knowledge base (Conway \& Rubin, 1993) as an empirical issue. On the one hand, it is possible that memories for events in one's life are essentially imagistic or purely conceptual and rendered linguistic only under certain circumstances and for certain purposes (e.g. "telling the memory"). On the other hand, it is also possible that aspects of such memories, or some subset of them, are encoded linguistically and preferentially retrieved linguistically.

In previous research, we have found that bilinguals can make a distinction between the internal language of retrieval and the external language of memory performance (Schrauf \& Rubin, 1998). That is, they experience a memory as coming to them in one language and then translate that memory into the other language according to the requirements of circumstances. In that work, we employed the Crovitz-Schiffman cuing technique (Crovitz \& Schiffman, 1974) and hypothesized that language of cue would affect retrieval of personal memories. Specifically, we predicted that cues in the mother tongue would trigger more memories from childhood and youth, whereas cues in the second language would trigger more recent memories. We tested 12 older bilingual immigrants (ages $61-69$ ) by presenting 50 word cues in one language on one day and 50 word cues in the other language on a second day and found no difference in the distribution of memories across the lifespan. That is, cues in the mother tongue did not retrieve earlier memories. This would seem to argue either for exceptional fluency (certainly possible for these bilinguals after 30 years in Anglo environments) or for non- 
linguistic, imagistic, or conceptual storage of autobiographical memories.

However, as part of the earlier experiment, we also asked participants to identify any memory that seemed to come to them in the language not being used during the test session. Participants identified approximately $20 \%$ of memories generated to Spanish cues on Spanish days as having come to them in English, and 20\% as coming in Spanish on days in which cues were in English. These memories, characterized by the internal language of retrieval, were in fact distributed across the lifespan in accord with our original predictions. That is, memories internally retrieved in the first language (Spanish) generally commemorated events from before adult immigration to the U.S., whereas second language (English) memories generally commemorated more recent events. This implies, first, that at least some memories are linguistic in nature (although others may not be) and, second, that linguistic aspects of the bilingual's memories may be stored in one or the other language in some enduring fashion. Bilinguals are particularly interesting in this regard, because if language is constitutive of memory, the possibility of comparing the differing dynamics of two languages within the same individual greatly enhances our chances of detecting it.

In this paper, we examine the phenomenological characteristics of bilinguals' autobiographical memories. We count the linguistic/nonlinguistic nature of retrieval as one of these. We are interested in whether the judgment that a memory has come in words correlates highly with other memory characteristics (sense of reliving, sensory detail, emotionality, and rehearsal) or whether it is an independent dimension of contrast. If the latter, we may be justified in saying that some autobiographical memories are encoded and internally retrieved linguistically, and, for the bilingual, in a specific language.

\section{METHOD}

Eight older Spanish-English bilingual immigrants participated in the study: 6 females and 2 males (mean age $=65.63, S D=2.77$ ) from Argentina (2), Cuba (3), Panama (2), and Spain (1). Their average age at the time of immigration was 28.00 years $(S D=6.02)$, with the result that they had lived in the United States an average of 37.63 years $(S D=4.00)$. It is important that the period of monolingual residence in the country of origin last through childhood and youth in order to provide the greatest contrast with the later, lengthy bilingual period. Persons meeting the requirements of adult immigration, 30 years of life in the U.S., and residence in predominantly Englishspeaking communities are not easily found. The participants for this study were recruited from a previous study of bilingual autobiographical memory (Schrauf \& Rubin, 1998). Of the 12 persons in that study, 8 were available and agreed to participate in the present research. For a full description of the sample, see the discussion of participants $1,3,4,7,8,9,10$, and 11 in the previous work. In particular, the participants for that study were chosen because of their high level of bilingual competence in both Spanish and English and high degree of acculturation to U.S. culture. All of these persons lived in English-speaking neighborhoods and had little contact with other Spanish-speaking persons outside their own families. All of them judged their competence in English relative to Spanish in understanding, speaking, reading, and writing as being at or above $90 \%$.

Each person participated in one Spanish and one English condition, hereafter referred to as the Spanish day and the English day, separated by approximately 2 weeks. Both sessions were conducted by the (bilingual) first author, and all conversation and testing were done in the language of the day.

The participants were presented with 16 cue words and were asked to associate freely the memory of an event from the personal past, with no attempt to select from older or more recent memories or from more important or trivial memories. The participants were instructed to make a written note of the content of the memory as soon as it came to them, with the allowance that such notes might be purely personal and need not reveal the content of the memory to the researcher (for the purposes of preserving privacy and diminishing editing effects).

The total set of 32 cue words were chosen from Rubin (1980) and adapted for Spanish in Schrauf and Rubin (1998). The lists were randomized, and half of each list was presented in one language on one day to a participant and the other half in the other language on a subsequent day to the same participant. The participants were paired so that the corresponding translations were presented to another person. Response time to memory was measured by stopwatch from the moment the participant flipped a cue card to the moment he or she began writing down the memory.

Since this study emphasized the "on-line" identification of the nonlinguistic/linguistic nature of recalls, the participants were asked immediately upon completion of the description to determine whether the memory seemed to come to them in: (1) no language, (2) Spanish, (3) English, (4) both languages (see Table 1, section A). Explanation of this effect was made by analogy to dreaming, in words similar to the following.

It is common for a bilingual person to say that he or she had a dream in
one or the other language, and we have found that for some bilingual
people, memories are like dreams in that way. Sometimes people say
that they dreamed in one or the other language, and sometimes in no
language at all, rather the dream seemed to be a series of images or
movements. Memories seem to come to people like that: sometimes in
images and sometimes in words. If you think that a particular memory
came to you in Spanish or English, please make a note of it. Sometimes
that sense is not strong, however. A memory might come vaguely or in-
distinctly in Spanish or English, or it may involve the very distinct per-
ception of words and phrases and sentences.

In a second question, the participants were asked to judge the linguistic intensity of the memory. This concept was explained in terms of a 7-point scale, where a mark of $1=$ no language element whatsoever, and a mark of $7=$ the memory comes very clearly in words. No further clarifications were provided (in fact, none were requested). After responding to these questions, the participants flipped the next cue card and initiated mental search for the next memory.

After recalling memories to 16 cue words and answering the preceding two questions regarding each memory, the participants were asked to return to each memory and rate the experience on several dimensions. The first question in this second set (Table 1, section B) addresses the distinction between "knowing that" an event took place in the past and "remembering" an event, which includes a sense of reliving or reexperiencing the event (Brewer, 1996; Hyman, Gilstrap, Decker \& Wilkinson, 1998; Rybash \& Monaghan, 1999). The next question (2) concerns emotional involvement and visual detail. Questions 4, 5, and 7 address the sensory content of recalls: imagery, hearing voices, and seeing written words. Question 6 asks what languages were spoken by persons in the memory, regardless whether they were actually speaking in the memory itself. Two questions ask for judged frequency of rehearsal, in thought (8) and in speech (9). Finally, the last series of questions concerns the place and time of the event (10-12). 
Table 1

Phenomenal Characteristics of Memories

A. Asked immediately after recall of each memory:

1. This memory came to me in: no language/Spanish/English/both languages

2. I would rate the intensity of this language experience as follows: (seven point scale)

$1=$ No language element whatsoever

$7=$ The memory comes to me very clearly in words

B. Asked for each memory after the participant had completed sixteen recalls.

Questions $1-3$ and 5 and 7 were rated as follows: $1=$ not at all, $3=$ vaguely, $5=$ distinctly, $7=$ as clearly as if it were happening right now.

1. Some memories come to you with a sense of reliving, others are just things that you know happened but do not come with a sense of reliving. As I recall this memory, I have a sense of reliving...

2. As I remember the event, I can feel now what I felt then with the same intensity ...

3. As I recall this event, I can see it in my mind ...

4. Images I get when I think of this event are like:

A. no image present

B. a photograph, motionless

C. a slideshow, a series of still images

D. a movie, moving images

5. In the memory, I can hear myself or other people talking ...

6. I usually spoke Spanish, English, or both with the persons in the memory (even if they were not talking in the memory itself).

7. In the memory I can see written words on a sign, in a note, in a newspaper, etc. ...

Questions 8-9 were rated as follows: $1=$ not at all, $3=$ sometimes, $5=$ many times, $7=$ as often as any event in my life.

8. Since it happened, I have thought about this event ...

9. Since it happened, I have talked about this event ...

10. Where does the event take place (home, school, restaurant, work, etc)?

11. In what city does the event take place?

12. Assign a date to the memory.

\section{RESULTS}

\section{General Phenomenal Characteristics of the Memories}

As noted earlier, autobiographical memories can range from those that are very vivid and include a sense of reliving to those that contain no more than the scant knowledge that an event took place. We asked the participants to rate their recalls on the sense of reliving and further fleshed out that sense by asking about emotional involvement, visual detail, and hearing voices. Table 2 presents the mean Pearson $r$ correlations for all 8 participants. The numbers in parentheses indicate the number of participants who had positive correlations. By a sign test, if 8 out of 8 participants had positive rather than negative correlations, the null hypothesis can be rejected at the $p<.01$ level (two-tailed test; for a one-tailed test, 7 out of 8 are significant at the $p<.01$ level). For each mean correlation, we also computed a single sample $t$ test against the null hypothesis of zero correlation. Significant correlations at the $p<.05$ level are marked in the table with asterisks. Note that for significant correlations in this test, either 7 or 8 participants had positive correlations. Though included in Table 2, the question regarding visual detail which asks whether the memory seemed to be more like a still image, a series of still images, or a movie showed little variability and will not be considered in these results.

For all 8 participants, the sense of reliving correlated positively with emotional involvement $(.76)$, visual detail (.79), and hearing voices (.48) in their memories. Visual detail and hearing voices were positively correlated for all 8 participants (.47). This suggests strongly that the sense of reliving a memory is driven by the sensory detail activated on recall (Brewer, 1996; Johnson, Suenegas, Foley, \& Raye, 1988; Rubin \& Greenberg, 1998). Positive correlations with the two rehearsal frequency judgments also suggest that memories rated highly on sense of reliving are frequently thought about and talked about as well. None of the measures of reliving or sensory detail correlated highly with participants' ratings of the linguistic intensity of their recalls. That is, memories judged to be more emotionally involving and to include visual detail and the hearing of voices are not judged to be specifically linguistic in nature.

\section{Four Categories of Internal Language of Memories}

To explore the linguistic nature of autobiographical recalls, one must distinguish (1) the nonlinguistic versus linguistic dimension of memories, and (2) the language of recall (here Spanish vs. English) dimension.

Since all recalls were cued in either Spanish or English and identified by the participants as having occurred in no language, Spanish, English, or both languages, each memory was assigned to one of four categories according to language of cue and language of recall. A nonlinguistic memory was a memory cued in either Spanish or English but recalled with "no language element whatsoever." A congruent memory was identified as having come to the person in the same language as that of the cue word: Spanish cue word-Spanish recall; English cue wordEnglish recall. A crossover memory was a memory cued in one language and remembered in the other language: Spanish cue word-English recall; English cue wordSpanish recall. The language of the retrieval "crosses over" from the language of the cue (from the language being used between experimenter and participant during the entire session) to the other of language of the bilingual participant. Finally, a both language memory was one cued by either language but identified as coming to the person in both languages. Table 3 presents this data by language of the day.

If the percentages for both days are averaged, the memories identified as nonlinguistic account for approximately $20 \%$ of the total. Of linguistic memories, almost half $(47 \%)$ were congruent; that is, recall occurred in the same language as did the cue. Comparison of the Spanish and English days, however, shows significantly more Spanish recalls per participant produced to Spanish cues 
Table 2

Phenomenal Characteristics of Autobiographical Memories: Mean Correlations for 8 Participants

\begin{tabular}{|c|c|c|c|c|c|c|c|c|c|c|}
\hline & $\begin{array}{l}\text { Language } \\
\text { Intensity }\end{array}$ & $\begin{array}{l}\text { Sense of } \\
\text { Reliving }\end{array}$ & Feel Now & See Now & $\begin{array}{c}\text { Images: } \\
\text { Like a }\end{array}$ & $\begin{array}{l}\text { Hear } \\
\text { Voices }\end{array}$ & $\begin{array}{l}\text { Written } \\
\text { Words }\end{array}$ & $\begin{array}{l}\text { Rehearse } \\
\text { Thought }\end{array}$ & $\begin{array}{c}\text { Rehearse } \\
\text { Told }\end{array}$ & $\begin{array}{l}\text { Nonlinguistic } \\
\text { vs. Linguistic }\end{array}$ \\
\hline Language intensity & - & $.14(6)$ & $.14(5)$ & $.09 \quad(6)$ & $.05(4)$ & $.28 *(8)$ & $.10(5)$ & .13 & $.18 \quad(7)$ & $.69 *(8)$ \\
\hline Sense of reliving & & - & $.76 *(8)$ & $.79 *(8)$ & $.33 *(7)$ & $.47 *(8)$ & $.00(4)$ & $.49^{*}(8)$ & $.41 *(7)$ & $.10(7)$ \\
\hline Feel now & & & - & $.70 *(8)$ & $.36 *(7)$ & $.44 *(8)$ & $.09(7)$ & $.55^{*}(8)$ & $.48 *(8)$ & $.04(5)$ \\
\hline See now & & & & - & $.36 *(7)$ & $.46^{*}(8)$ & $.04(5)$ & $.50^{*}(8)$ & $.46 *(8)$ & $.01 \quad(4)$ \\
\hline Images: Like a & & & & & - & $.19 \quad(7)$ & $.17(6)$ & $.22 \quad(6)$ & $.19(6)$ & $.01 \quad(5)$ \\
\hline Hear voices & & & & & & - & $-.03(4)$ & .39 & $.39(7)$ & $.19(7)$ \\
\hline Written words & & & & & & & - & .14 & .13 (4) & $.08 \quad(7)$ \\
\hline Rehearse thought & & & & & & & & - & $.82^{*}(8)$ & .09 (5) \\
\hline Rehearse -told & & & & & & & & & - & $.12(5)$ \\
\hline Nonlinguistic versus linguistic & & & & & & & & & & -- \\
\hline
\end{tabular}

Note-Numbers in parentheses indicate number of correlations that were positive out of eight total. $\quad{ }^{*} p>.05$ using a one-sample $t$ test against the null hypothesis of zero correlation.

on the Spanish day (59\%) than English recalls produced to English cues on the English day $[36 \% ; t(7)=4.08$, $p<.01]$. This is balanced in part by the fact that on English days, cues in English produced more crossover recalls in Spanish.

Crossover memories are of particular interest for both empirical and theoretical reasons. Empirically, the proportion of memories identified as crossovers in this experiment $(25 \%)$ is consistent with the proportion $(20 \%)$ identified by the same subjects in the previous study (constituting a replication of that work). Theoretically, crossovers may constitute the strongest linguistic memories, since they are recalled against the language of the day - that is, in the less activated language of the test session. Finally, memories recalled in both languages account for only $7 \%$ of the total recalls.

\section{Categories of Internal Language of Memories and Response Times}

Response times measured in seconds from turning the cue card to recording the memory were equivalent for all of the categories of recall: nonlinguistic $(M=21.48 \mathrm{sec}$, $S D=12.01)$, congruent $(M=20.99 \mathrm{sec}, S D=7.17)$, crossover $(M=19.28, S D=6.17)$, and both languages

Table 3

Memories by Internal Language of Recall

\begin{tabular}{lccccc}
\hline & \multicolumn{3}{c}{ Percent of Recalls } & & \multicolumn{2}{c}{ Age at Memory } \\
\cline { 2 - 3 } \cline { 5 - 6 } Internal Language & $\%$ & $S E$ & & $M$ & $S E$ \\
\cline { 1 - 2 } Nonlinguistic & \multicolumn{3}{c}{ Spanish Day } & & \\
Congruent (Spanish) & 59 & 7 & & 28.55 & 3.30 \\
Crossover (English) & 21 & 7 & & 52.89 & 4.14 \\
Both languages & 2 & 2 & & 40.43 & 13.57 \\
All memories & 100 & & 34.75 & 3.43 \\
& English Day & & \\
Nonlinguistic & 22 & 6 & & 24.57 & \\
Congruent (English) & 36 & 5 & & 48.20 & 3.82 \\
Crossover (Spanish) & 30 & 4 & & 26.92 & 3.98 \\
Both languages & 12 & 4 & & 38.94 & 6.94 \\
All memories & 100 & & 36.74 & 3.47 \\
\hline
\end{tabular}

Note-Mean age refers to the average age at which the event remembered occurred.
$(M=18.31, S D=11.01)$. No significant difference was found between these means $\left[F(3,26)=0.17, M S_{\mathrm{e}}=\right.$ 86.15, n.s.]

\section{Categories of Internal Language of Memories and Phenomenal Characteristics of Memory}

Memories distinguished along the linguistic versus nonlinguistic dimension and along the language of recall dimension do not seem to have differed in any other way. That is, they were not more or less vivid, emotionally engaging, or likely to include hearing voices or seeing written words. Their rehearsal patterns were also similar.

For each of the questions concerning sense of reliving, visual experience, emotional involvement, evidence of written words, and the two rehearsal scales, scores were averaged for each individual for each category (Table 4). Single-factor analyses of variance were done to test for significant differences between the means of correlations in the nonlinguistic, congruent, and crossover recall categories. The both languages category was omitted from these analyses because 3 participants did not have retrievals in one or both of the cuing (Spanish or English) conditions. No significant differences were found between recall categories for sense of reliving $[F(2,21)=0.54$, $M S_{\mathrm{e}}=0.74$, n.s.], emotional involvement $[F(2,21)=$ $0.16, M S_{\mathrm{e}}=0.63$, n.s.], visual reexperience of memories $\left[F(2,21)=0.07, M S_{\mathrm{e}}=0.61\right.$, n.s. $]$, evidence of written words $\left[F(2,21)=0.26, M S_{\mathrm{e}}=0.38\right.$, n.s. $]$, and the two rehearsal measures [think, $F(2,21)=1.31, M S_{\mathrm{e}}=0.75$, n.s.; talk, $F(2,21)=1.00, M S_{\mathrm{e}}=0.79$, n.s.]. A significant difference among means in the four categories of internal language of recall was found for judgments of language intensity $\left[F(2,23)=53.50, M S_{\mathrm{e}}=0.61, p<.001\right]$ and for hearing voices $\left[F(2,21)=3.50, M S_{\mathrm{e}}=0.68, p<\right.$ $.05]$. Not surprisingly, memories judged to have come in no language have the lowest mean linguistic intensity rating. Memories judged to be linguistic (i.e., congruent, crossover, or both) have high means. A similar pattern occurred for hearing voices, which shows a progression of scores from nonlinguistic memories to linguistic memories; this suggests greater awareness of voices in memories identified as coming in a specific language. Nevertheless, 
Table 4

Mean Ratings of Phenomenal Characteristics of Recalls

by Internal Language of Recall

\begin{tabular}{|c|c|c|c|c|c|c|c|c|}
\hline \multirow{2}{*}{$\begin{array}{l}\text { Phenomenal } \\
\text { Characteristic }\end{array}$} & \multicolumn{2}{|c|}{ Nonlinguistic } & \multicolumn{2}{|c|}{ Congruent } & \multicolumn{2}{|c|}{ Crossover } & \multicolumn{2}{|c|}{ Both } \\
\hline & $M$ & $S D$ & $M$ & $S D$ & $M$ & $S D$ & $M$ & $S D$ \\
\hline Sense of reliving & 4.63 & & 5.0 & & 5.00 & & 5.48 & 1.37 \\
\hline Feel as if now & & & & & & & & 0.71 \\
\hline See as if now & 5.04 & 0.7 & 5.03 & & 5.17 & 87 & 5.26 & 0.63 \\
\hline Hear voices & 3.30 & 0.7 & 12 & 64 & .35 & .06 & 4.67 & 0.83 \\
\hline Written words & 1.55 & 0.8 & 1.74 & 0.43 & .75 & .56 & 1.79 & 1.37 \\
\hline Rehea & 3.2 & & 3. & & 3.8 & 0.94 & 3.89 & 0.75 \\
\hline & 2.61 & 1.0 & 2.97 & 0.79 & 3.24 & 0.87 & 3.54 & 0.78 \\
\hline Language intensity & 1.47 & 0.15 & 5.21 & 1.53 & 4.71 & 1.63 & 5.40 & 1.77 \\
\hline
\end{tabular}

participants were aware of voices even in nonlinguistic memories. Interestingly, neither nonlinguistic nor linguistic recalls had representations of written words in the contents of the memories. That is, few examples of words on signs or in notes or newspapers were contained in the memories. On the other hand, all four categories of recall involved hearing voices.

Thus, for the phenomenal characteristics - sense of reliving, emotional involvement, and visual detail-little difference emerges between recalls that were nonlinguistic and those that were linguistic (congruent, crossover, and both language). However, this basic distinction between nonlinguistic and linguistic recall is very clearly reflected in other ways in the data.

\section{The Nonlinguistic Versus Linguistic Distinction}

The nonlinguistic/linguistic distinction is well attested in the psychology of language literature (e.g. dual coding theories; Paivio, 1991a, 199 lb, 1991c), and it emerges clearly in these data as well. In simple quantitative terms, the mean number of linguistic retrievals on any given day for these participants (25.40) was far greater than the number of nonlinguistic retrievals (6.40).

More intricate, however, is the underlying continuum of language intensity - that is, the degree of explicit involvement of words in a recall. Immediately after each recall, the participants rated each memory on a 7-point scale as having involved from $1=$ no language element whatsoever to $7=$ the memory comes to me very clearly in words. Participant responses on the language intensity scale were consistent with the recall categories: memories designated nonlinguistic had a mean language intensity score of $1.47(S D=0.15)$. Those designated linguistic (i.e., congruent, crossover, or both languages) had a mean of 5.0 $(S D=1.60)$. Furthermore, by assigning a score of 0.0 to each nonlinguistic memory and a score of 1.0 to each linguistic memory (congruent, crossover, and both language), we formed a second (simpler) scale. The mean correlation between this scale and the participants' judgments of language intensity was high (.69), and 8 of 8 participants showed positive correlations between these scales (Table 2).

The language intensity scales (participants' judgments and the nonlinguistic/linguistic scale) did not correlate highly with sense of reliving, emotional involvement, or visual detail (Table 2). That is, explicit recall in words did not correlate with higher ratings of visual detail, hearing voices, emotionality, or rehearsal frequencies. This is consistent with the report that there is no difference in mean scores or correlations of phenomenal characteristics across recall categories. Again, the phenomenal characteristics of a memory did not predict its identification as nonlinguistic or linguistic.

Thus, undergirding the difference between nonlinguistic and linguistic recalls there seems to be a continuum of language intensity of memory. This is a construct that we do not understand well at this point, but at one end of the continuum lies very clear recall in words and at the other a shading off into some vague awareness of language elements. However understood, the distinction does not correspond to level of sensory detail in the memory. The discrimination between nonlinguistic and linguistic memories does not seem to be due to the presence or absence of voices and conversation in the content of the memories but rather to a coding of the memory in words.

\section{Recall in Spanish or English}

If it is the case that some autobiographical memories are essentially linguistic retrievals, we would expect to see that the linguistic context at encoding would leave its mark on retrieval. Events originally encoded in the participant's Spanish linguistic context would be preferentially retrieved in Spanish; those from an English linguistic context would be retrieved in English. This is precisely what we see.

In addition to numbers of recalls by language and category, Table 3 also gives the mean age of the participants at the time of the events remembered. Immediately apparent is that events recalled in Spanish were from much earlier in life than events recalled in English. This is true for congruent memories: The reported mean age at time of events cued and recalled in Spanish was 28.55, and of events cued and recalled in English, $48.20[t(7)=4.09$, $p<.01]$. The distribution of these memories across the lifespan is represented in Figure 1.

The same is true for crossover memories (Figure 2). Memories cued in English but retrieved in Spanish commemorated events much earlier in life $(M=26.92)$ than 


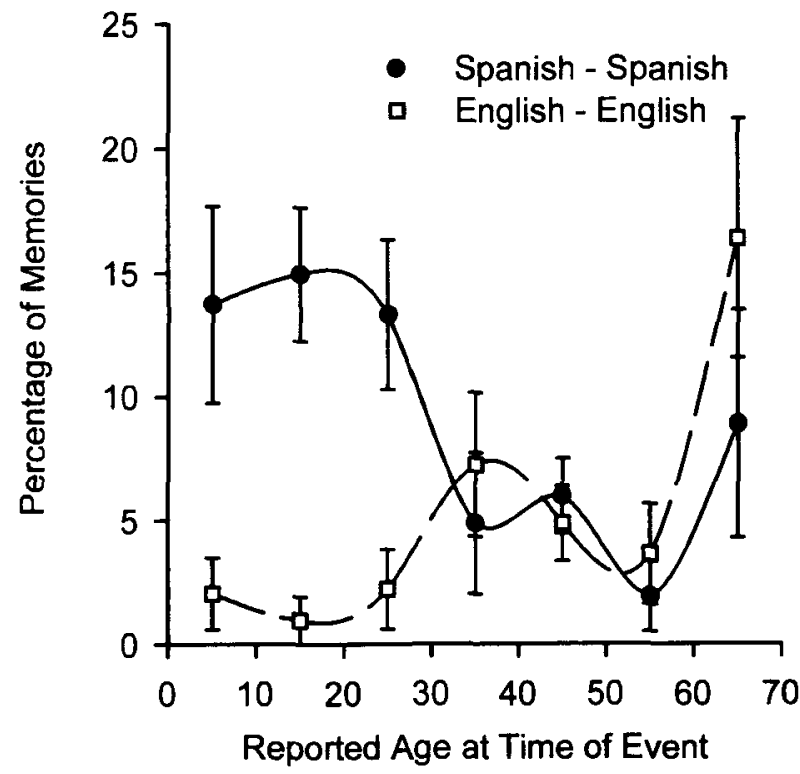

Figure 1. Histogram of congruent autobiographical memories cued in Spanish and retrieved in Spanish and memories cued in English and retrieved in English. Error bars show standard errors.

those cued in Spanish and retrieved in English $(M=$ 52.89). This difference is significant $[t(5)=8.85, p<$ .01 ], though 2 participants reported no crossover memories from Spanish to English. Both Figures 1 and 2 indicate a rise in memories recalled in English after the mean age of immigration $(M=28.00)$ for these participants.

For the sake of comparison, nonlinguistic memories are shown in Figure 3, here differentiated by the language of cue being used on the day of testing. Although, on the average, nonlinguistic memories produced on English days commemorated events from earlier in life $(M=24.57)$ than did those recalled on Spanish days $(M=37.87)$, a $t$ test showed no significant difference in these means $[t(4)=1.35]$ - though 2 participants reported no nonlinguistic memories in response to Spanish cues and 1 participant reported no nonlinguistic memories in response to English cues. The histogram (Figure 3) shows little difference in the shapes of the distributions of the memories across the lifespan. Nonlinguistic memories do not seem to have been preferentially recalled in one or the other language since their retrieval seems not to have engaged the linguistic faculty. (For recalls in both languages, the distributions resulted in curves similar to those of nonlinguistic memories, but they are not shown because the small number of retrievals in this category render interpretation unclear.)

The phenomenon of crossover memories in particular provides evidence that certain autobiographical memories are memories in words. Events that took place in the cognitive context of the first language, at a time when the first language was uncontested by any other, were more often retrieved in the first language, even when that language was not selected as the base language of the experimental session. They exhibit a kind of incorrigibility and persistence whose origin (it is argued here) must be found in the linguistic encoding of the memory. Conversely, events that took place later in life, during a time when a second linguistic code was developing in a second cognitive, linguistic context, were more often retrieved in the second language. Their number is fewer; the phenomenon was weaker, due in part to the bilingual cognitive context in which encoding and retrieval take place. Put simply, memory retrievals bear the imprint of linguistic encoding. Linguistic context at time of encoding is reflected in the language specific nature of retrievals, as would be expected by encoding specificity (Tulving \& Thompson, 1973). The contextual information stored at encoding includes the language spoken by the person at the time.

\section{Summary}

The experience of the recall of events from the personal past may be linguistic or nonlinguistic. There is little discernible difference between nonlinguistic and linguistic memories concerning vividness or sense of reliving: Sensory dimensions (seeing details or hearing voices) and emotional involvement (feeling now what was felt then) are equally likely features of both types of memories. Likewise, it is rare to find evidence of written words in either nonlinguistic or linguistic memories. Furthermore, since no correlation emerged between participants' judgments of linguistic intensity and their perception of hearing voices and/or seeing written words in the content of memories, we suggest that the "sense of language" in the retrieval experience corresponds to a linguistic coding of

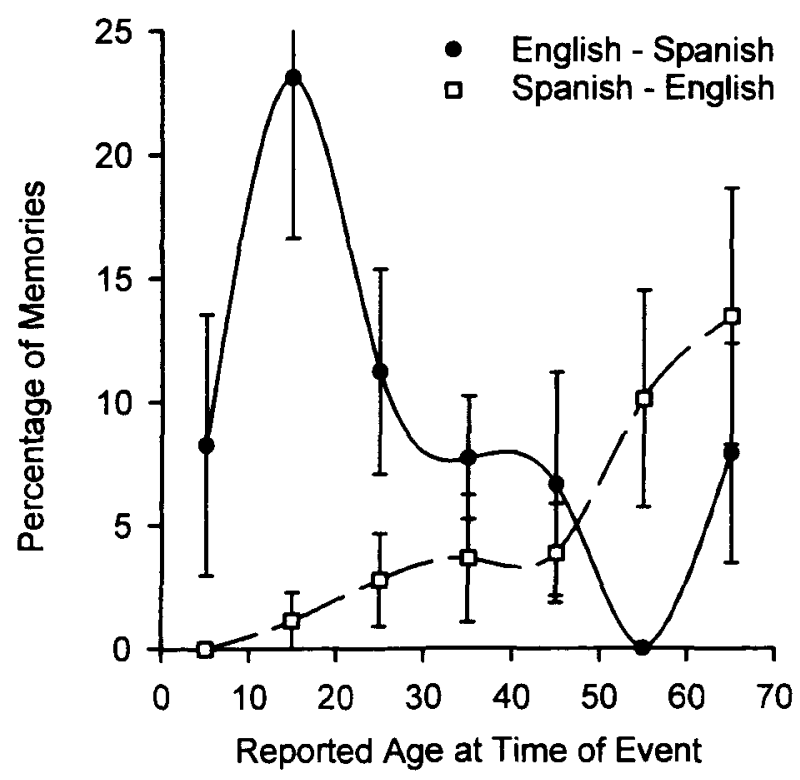

Figure 2. Histogram of crossover autobiographical memories cued in English and retrieved in Spanish and memories cued in Spanish and retrieved in English. Error bars show standard errors. 


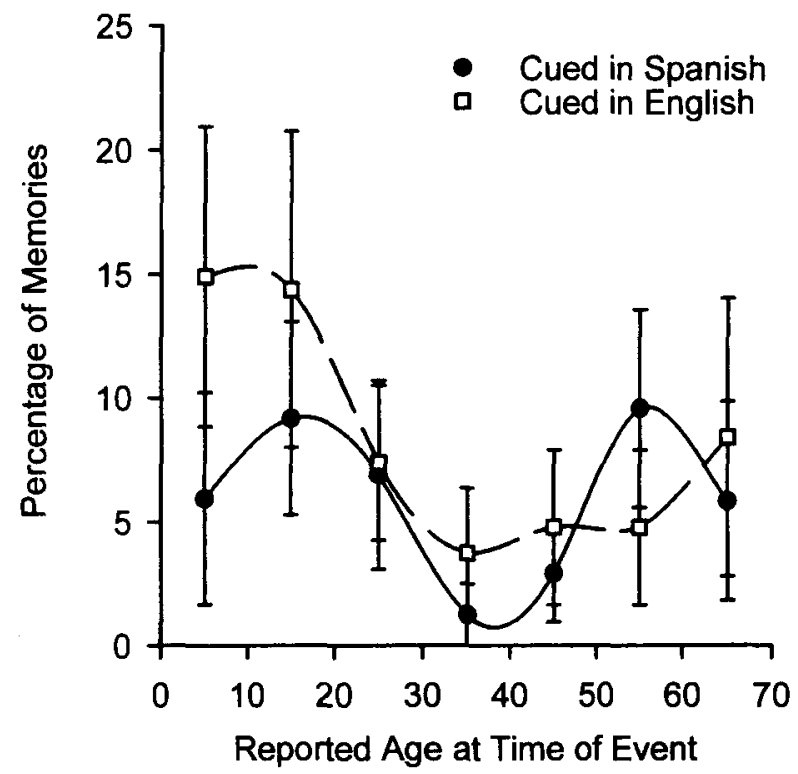

Figure 3. Histogram of nonlinguistic memories cued in Spanish on the day of Spanish testing and cued in English on the day of English testing. Error bars show standard errors.

the memory-that "the memory comes in words." This linguistic intensity is variable. Linguistic memories may be more or less so. Memory in words seems particularly clear when persons are bilingual. For example, a person's memories for events encoded in the cognitive and linguistic context of her childhood in Argentina may be retrieved internally in Spanish but related conversationally in English. On this view, nonlinguistic memories are imagistic. They are reactivations of primary sensory information such as visual and auditory information. Linguistic memories, by contrast, may contain such information but are mentally mediated by explicitly linguistic processes.

In sum, in our previous work with bilinguals, we found that they could distinguish the internal language in which a memory came to them from the external language being used in conversation. Since this implied that some autobiographical memories might by encoded and retrieved in a specifically linguistic state, we were led to examine the phenomenological characteristics of such memories. On the basis of this research, we conclude that the judgment that a memory "came in words" or that it did not is a fundamental dimension of contrast independent of other memory characteristics, such as sense of reliving, amount and kind of sensory detail, emotionality, and rehearsal. The internal language of retrieval points to an underlying, specifically linguistic, memory that is stable over time and that reflects the language used at the time of encoding.

\section{REFERENCES}

BREWER, W. F. (1996). What is recollective memory? In D. C. Rubin (Ed.), Remembering our past: Studies in autobiographical memory (pp. 19-66). Cambridge: Cambridge University Press.
CoNWAY, M., \& RuBIN, D. C. (1993). The structure of autobiographical memory. In A. F. Collins, S. E. Gathercole, M. A. Conway, \& P. E. Morris (Eds.), Theories of memory (pp. 103-137). Hillsdale, NJ: Erlbaum.

Crovitz, H. F., \& Schiffman, H. (1974). Frequency of episodic memories as a function of their age. Bulletin of the Psychonomic Society, 4, 517-518.

DE Groot, A. M. B. (1992). Bilingual lexical representation: A closer look at conceptual representations. In R. Frost \& L. Katz (Eds.), Orthography, phonology, morphology, and meaning (pp. 389-412). Amsterdam: Elsevier.

DE GroOT, A. M. B. (1993). Word-type effects in bilingual processing tasks: Support for a mixed representational system. In R. Schreuder \& B. Weltens (Eds.), The bilingual lexicon (pp. 27-51). Amsterdam: John Benjamins.

DE Groot, A. M. B., \& Com JIS, H. (1995). Translation recognition and translation production: Comparing a new and old tool in the study of bilingualism. Language Learning, 45, 467-509.

DE GROOT, A. M. B., \& HoEks, C. J. (1995). The development of bilingual memory: Evidence from word translation by trilinguals. Language Learning, 45, 683-724.

DE Groot, A. M. B., \& NAS, G. L. J. (1991). Lexical representation of cognates and noncognates in compound bilinguals. Journal of Memory \& Language, 30, 90-123.

Hyman, I. E., Gilstrap, L. L., Decker, K., \& Wilkinson, C. (1998). Manipulating remember and know judgments of autobiographical memories: An investigation of false memory creation. Applied Cognitive Psychology, 12, 371-386.

Johnson, M. K., Suenegas, A. G., Foley, M. A., \& Raye, C. L. (1988). Phenomenal characteristics of memories for perceived and imagined autobiographical events. Journal of Experimental Psychology: General, 117, 371-376.

KROLL, J. [F.], \& CURLEY, J. (1988). Lexical memory in novice bilinguals: The role of concepts in retrieving second language words. In M. Gruneberg, P. Morris, \& R. Sykes (Eds.), Practical aspects of memory (Vol. 2, pp. 389-395). London: Wiley.

KROLL, J. F., \& DE GROOT, A. M. B. (1997). Lexical and conceptual memory in the bilingual: Mapping form to memory in two languages. In A. M. B. de Groot \& J. F. Kroll (Eds.), Tutorials in bilingualism: Psycholinguistic perspectives (pp. 169-199). Mahwah, New Jersey: Erlbaum.

KROLL, J. F., \& ShOLL, A. (1992). Lexical and conceptual memory in fluent and nonfluent bilinguals. In R. J. Harris (Ed.), Cognitive processing in bilinguals (pp. 191-204). Elsevier.

Kroll, J. F., Sholl, A., Altarriba, J., Luppino, C., Moynihan, L., \& SANDERS, C. (1992, November). Cross-language semantic priming: Evidence for independent lexical and conceptual contributions. Paper presented at the 33rd Annual Meeting of the Psychonomic Society, St. Louis.

Kroll, J. F., \& Stewart, E. (1990, November). Concept mediation in bilingual translation. Paper presented at the 31 st Annual Meeting of the Psychonomic Society, New Orleans.

Kroll, J. F., \& STEWART, E. (1994). Category interference in translation and picture naming: Evidence for asymmetric connection between bilingual memory representations. Journal of Memory \& Language, 33, 149-174.

Paivio, A. (1991a). Dual coding theory: Retrospect and current status. Canadian Journal of Psychology, 45, 255-287.

PAIvio, A. (1991b). Images in mind: The evolution of a theory. London: Harvester Wheatsheaf.

PAIvio, A. (1991c). Mental representation in bilinguals. In A. G. Reynolds (Ed.), Bilingualism, multiculturalism, and second language learning: The McGill conference in honor of Wallace E. Lambert (pp. 113-126). Hillsdale, NJ: Erlbaum.

RUBIN, D. C. (1980). 51 properties of 125 words: A unit analysis of behavior. Journal of Verbal Learning \& Verbal Behavior, 19, 736-755.

RUBIN, D. C. (1998). Beginnings of a theory of autobiographical remembering. In C. P. Thompson, D. J. Herrman, D. Bruce, J. D. Read, D. G. Payne, \& M. P. Toglia (Eds.), Autobiographical memory: Theoretical and applied perspectives (pp. 47-67). Mahwah, NJ: Erlbaum.

Rubin, D. C., \& GReEnBerG, D. (1998). Visual memory-deficit amnesia: A distinct amnesic presentation and etiology. Proceedings of the National Academy of Sciences, 95, 5413-5416. 
Rybash, J. M., \& Monaghan, B. E. (1999). Episodic and semantic contributions to older adults' autobiographical recall. Journal of General Psychology, 126, 85-96.

SChRAUF, R. W. (in press). Bilingual autobiographical memory: Experimental studies and clinical cases. Culture \& Psychology.

Schrauf, R. W., \& RUBIN, D. C. (1997, October). Remembering in the other language: Bilingual/bicultural memory for the personal past. Poster presented at the Fifth Biennial Meeting of the Society for Psychological Anthropology, San Diego.

Schrauf, R. W., \& RubiN, D. C. (1998). Bilingual autobiographical memory in older adult immigrants: A test of cognitive explanations of the reminiscence bump and the linguistic encoding of memories. Journal of Memory \& Language, 39, 437-457.

Tulving, E., \& Thompson, D. M. (1973). Encoding specificity and retrieval processes in episodic memory. Psychological Review, 80, 352-373.

(Manuscript received September 28, 1998; revision accepted for publication July 16, 1999.) 